\title{
ISSUES RELATED TO TRANSPORT SECTOR ENVIRONMENTAL IMPACT ASSESMENTS (EIA)-EXPERIENCE IN SRI LANKA
}

\author{
JMSJ Bandara \\ Department of Civil Engineering, University of Moratuwa, Moratuwa
}

The objective of an EIA report is to ensure that the development options under consideration are environmentally sound and sustanable and environmental consequences are recognized and taken in to account early in the project design.

A number of EIA reports related to transport sector projects have been prepared during the last 10 years in Sri Lanka. They cover new expressway /highway projects and railway extensions. However, only highway related rejicts have been opened for public comments and have sought the approval of the project-approving agency. A careful evaluation of these reports clearly indicate that they have not fulfilled the objectives of an EIA even though they appear to satisfy the terms of reference (TOR) given by the project approving agency.

There are number of reasons for $n$ t achieving the objectives of the EIA exercise. The main reason is the consideration of the EIA report as the document on which the decision to go ahead with the project is determined. Tharefore, these EIA reports are heavily biased towards the preferred alternative and report prepareres have tried to justify the project rather than critically evaluate the impacts due to the project. This is clearly evident from the selection of alternatives. In many situations the comparison is restricted among the alternatives considered for the feasibility study and not even the no-option alternative has been considered.

Failure to identify the magnitudes and significance of the impacts in a logical manner has resulted in neglecting the mitigatory measures for some of the important aspects. Lack of coordination among the EIA team nembers and lack of communication between the EIA team and the project proponent have contributed heavily towards submitting poorly compiled reports with contradicting statements and ir relevant information. Detailed discussions on insignificant aspects and insufficient material related to significant impacts are very frequent in these reports. Transport related impacts are often reglected due the absence of a transport expert in most of the EIA teams.

Not using an appropriate methodology to evaluate and compare the alternatives is another shortcoming that can be observed. In many situations this has been exploited to justify the preferred alternative qualitatively.

It is very important to emphasis the intended role of an EIA report to the project proponent and to the EIA team so that they are encouraged to properly identify and propose mitigatory measures for the anticipated impacts. Additional burden of re-justifying the project should not be entrusted upon the EIA team once the project is selected based on a proper feasibility study. Emphasis should be given to identify and propose suitable mitigatory measures and monitoring mechanism so that the designers and operators are aware of the problems 